\title{
ON THE PATH OF THE BUDDHA - SPECIFICS AND DISTRIBUTION OF BUDDHISM IN BULGARIA
}

\author{
Svetoslava Toncheva \\ Comparative Folklore Studies Department, Institute of Ethnology and Folklore \\ Studies with Ethnographic Museum, Bulgarian Academy of Sciences \\ e-mail:svetahet@abv.bg
}

\begin{abstract}
The article deals with an unexplored topic in Bulgarian anthropological context - the distribution and specifics of Buddhism in Bulgaria. It aims at providing information about the penetration of Buddhism in the country and the state of the Buddhist communities at the present moment. Suggesting that Buddhism should be studied within the paradigm of the new spirituality/new religiousness, it attempts to view this specific worldview in the context of its global distribution in the Western world.
\end{abstract}

Keywords: Buddhism, Bulgaria, global, new religious movements

\section{Introduction}

In the last decades we observe "the return" of the religiousness not only in its traditional forms but also as various new religious movements/New Age including exotic religions such as Buddhism. The Buddhist ideas of compassion and nonviolence, the comparisons of its principles with the achievements of quantum physics and neurobiology (Yong 2008), its powerful influence on the Western psychology (Virtbauer 2012), the charm and mysticism of the East, 
the idea of relieving the suffering, the transformation and achieving happiness on the path to enlightenment are part of the reasons for its large distribution in the West ${ }^{1}$ that has reached unprecedented levels over the last 20 years. This postmodern or global Buddhism is synchronised with the characteristics of the contemporary period: pluralism, hybridity, ambivalence, globality and lack of territoriality. It seems adaptable to the Western world, offering varied traditions and practices, democratic principles, moral norms, and, above all, with its emphasis on the rational in synchrony with the modern science (Barker \& Rocha 2011: 10).

Its transnational distribution has led to the formation of an international or "cyber" Buddhist sangha, mobile teachers, international centres and contacts. The purpose of this article is to introduce the subject of Buddhism in Bulgaria into the ethnological/anthropological discourse and serve as a basis of future (and comparative) analysis of the transnational distribution of this religious denomination. It presents the distribution and specifics of the various Buddhist schools in Bulgaria in the context of the global studies of Buddhism in the West. The article has been prepared on the basis of fieldwork performed between May and October 2016 among various Buddhist communities in the country including Nyingma, Kagyu, Bon, Zen, etc. This approach defines the methodology of the research, based on well established anthropological approaches: interviews (structured and semi-structured), questionnaires and participant observation.

\section{Buddhism in Bulgaria}

Buddhism in Bulgaria is established in the context of the distribution and specifics of global Buddhism: pluralism and heterogeneity, traditionally oriented centres and forms of "Western Buddhism". In the context of two types of Buddhism, according to Prebish (1993) - of migrants and converted to Buddhism the one in Bulgaria falls completely within the second category. M. Baumann demonstrates within his classification of Buddhism as traditionalist and modernist (Baumann 2001), that those converted to Buddhism follow predominantly its modernist interpretations. As we are going to observe, however, in Bulgaria exists a trend of search of authenticity and avoidance of the Western forms of modernist Buddhism. 
Buddhism found a niche in Bulgaria after the changes in 1989 and began to distribute in the form of communities within the various Buddhist schools (predominantly of Tibetan Buddhism). This process begins symbolically with the visit of the Dalai Lama in Bulgaria in 1991. Since the 1990s, various Buddhist communities were established, some of which had disappeared over time (for instance Sakya) while others have been transformed and modified to reach the state we observe them today. Conditionally, without analysing how authentic the practiced Buddhism is, but on the basis of the methods of its dissemination, several basic forms of Buddhism can be distinguished in Bulgaria:

- "Western model" or Buddhism distributed by the Europeans (Lama Ole Nydahl);

- “authentic Buddhism", distributed by teachers from the East (mainly India and Tibet - Drikung Kagyu, Nyingma, Gelug, Bon) and Japanese Buddhism (Zen), which is more specific and related to martial arts.

Apart from this classification, each of the different types of Buddhism has its own specifics that will be presented below.

\section{The "Western" Model - The Diamond Way of Buddhism (Lama Ole Nydahl)}

The most widespread form of Buddhism in Bulgaria is the so called Diamond Way of Buddhism - a Tibetan Buddhism from the tradition of Karma Kagyu, spread in the West by the Danish Ole Nydahl. The term "diamond way" originates from vajrayana (sanskrit, 'dorje tegpa' - Tibetan) - the diamond or the most perfect gem, in connection with the idea that these are Buddha's sublime teachings. Lama Ole Nydahl is a qualified lama and meditation teacher in this particular Buddhist tradition ${ }^{2}$, a student of the $17^{\text {th }}$ Karmapa Thaye Dorje. In 1972, he was sent by him to teach Buddhism to the West, becoming the most successful European, spreading Buddhism beyond its original context, creating more than 650 Diamond Way Centres in 44 countries around the world (Diamond Way 2016). The possibility of meeting a living llama, the personal contact with him, the transmission of Buddhism into the language of the Europeans, the knowledge of the cultural specifics, etc. makes the Buddhism of Lama Ole leading not only in Europe, but also in Bulgaria. 
The school of the Diamond Way spread in Bulgaria in 1992, when people associated with Zen Buddhism invited Lama Ole to deliver his first lecture in Bulgaria. The following year he arrived again, and in 1994 he visited Varna when already organised groups of followers (including one in Sofia) awaited him. Today the community has its own centres in various cities in the country. Retreat centres were built in Vinitsa (Varna), Kovachevitsa and near the village of Plana where the first Buddhist stupa in Bulgaria was built.

The stupa has now turned into a symbol of Buddhism in Bulgaria, being visited not only by the members of the community and other Buddhist communities, but by Lama Ole and various Tibetan teachers, as well. Besides being sacred, the place is also associated with an interesting miraculous story. It was discovered in 2007 and is pointed out by Lama Ole Nydahl as the place of the "loving eyes" (Chenrezig - the Tibetan name of Avalokiteshvara). After geological surveys it becomes clear that the chosen place is not accidental because when Vitosha was a volcano, it was tearing lava, and de facto a deep stream came out from the ground, a tongue of lava like a hand pointing to the south ... and on the palm there was just enough space to build the stupa. And the place indicated by the lamas is right here ... and both of them - Lama Ole and Sherab Gyalzen Rinpoche pointed this place and route (AIF I No. 511: 9-10). In the construction of the stupa on the tree placed in the centre, the colours of the Bulgarian flag miraculously appeared, and Sherab Gyaltsen Rinpoche, who sanctifies it, donated his last relict from Buddha.

For about the last ten years, the organisation has been registered as a religious community under the Religious Denominations' Act of Bulgaria. Its membership, like in other Buddhist communities, is informal, although a list of members is maintained. The principle of membership is based on the Kagyu tradition, in which initially the student "tests" the teacher for three years in order to assess whether he can fully work and activate such a type of qualities as the teacher possesses (AIF I No. 511: 7). In the second stage the teacher "tests" the student if he/she can cope with the requirements of the school. In case of full agreement an intensive training begins. Because one can hardly find six years in the Western world, here one relies on a more intense exchange of information, but this condition still exists (AIF I No. 511: 7).

While the Diamond Way in Bulgaria is a well-organised community, particularly the strongest example of consolidation is the sangha in Rousse, where Buddha House - a cultural and meditation centre including a complex 
of gompa's (places for meditation), living apartments, a library with a café, a seminar hall was built. Lectures on various topics related to Buddhism are being delivered there weekly. The aim of the centre is to enable people interested in Buddhism to obtain information and have conditions to practice it (FnAIF No. 2919). This factor leads to the formation of one of the largest communities in the country, which is a model for the daily realisation of the Buddhist ideals - we are gathered around this idea, to develop the centre, work for the place, support the work of Lama Ole (FnAIF No. 2919).

The "serious" followers of the Diamond Way in Bulgaria number about 200 people, while there are many temporary members or just sympathetic ones, who don't strictly follow the practices and philosophy. At the same time, the organisational form of the community is important in order to provide the necessary information and methods, practices, and the continuity of these teachings so that anyone who wants can begin to study them (AIF I No. 511: 8).

As I mentioned at the beginning, the main feature of global Buddhism is mobility. Mobile are also the members of the Diamond Way. They travel not only around Bulgaria on occasions of lectures, retreats and seminars, but also around the world, including accompanying Lama Ole Nydahl in his travels. At the same time, teachers from all over the world are being invited and international seminars are organised around Lama Ole's activities. Distinctive about the organisation and the opportunities for practicing Buddhism in Bulgaria is even the disappointment of the travel of members of the community to Bhutan, where, according to them there is no true Buddhism (FnAIF No. 2919).

The education in the Diamond Way of Buddhism follows several stages: introduction meditation (guru-yoga), known also as Meditation of the $16^{\text {th }}$ Karmapa. It is followed by the four Foundational Practices (Ngöndro) aimed at realising the true nature of the mind. Following meditations are practised: Loving Eyes Meditation (Chenrezig - for developing sympathy and compassion), Meditation of the eighth Karmapa (Practice of Devotion), Black Cloak (Vajra Mahakala, meditation to acquire Courage) and Phowa (conveyance of consciousness) (see more Diamond Way 2016).

There is a lot of information concerning the Diamond Way in Bulgaria, not only due to the well-organised centres and the available literature, but also because of the media participations of Lama Ole Nydahl. International events such as the New Year's Course of Lama Ole Nydahl and Jigme Rinpoche in Sofia in December 2016 are often organised in Bulgaria. All of these factors contribute to the relatively wide distribution of this type of Buddhism in the country. 


\section{"Authentic" Buddhism}

\section{Drukpa Kagyu}

The most striking example of the search for authentic Buddhism, taught by an authentic teacher offering education in real Buddhism, is observed among the followers of Drukpa Kagyu. It represents a lineage of the Tibetan Buddhism and one of the eight sub-lineages of the Kagyu tradition, originating from Tsangpa Gyare (1161-1211). In Bulgaria, it is represented by the Bodhichita Foundation with president Acharya Khenpo ${ }^{3}$ Ramesh Negi with a branch of Khampagar monastery Tashi Jong, India (Togdens 2016) in the town of Kazanlak. Bulgarians had also built an educational centre in Buddhism in Rewalsar, India.

The penetration of the Drukpa Kagyu is a result of the efforts of a psychologist for whom the Buddhism in the West is presented in a fragmented way through fragmented concepts and techniques that have nothing in common with Buddhism (AIF I No. 511:24), that is a holistic, unified system. Buddhism is seen as the only psychological science because Western psychology deals only with the surface of the mental functioning, conscious functioning, and does not even offer a theory of the deep layers of the unconscious. Buddhism, on the other hand, within its 108 volumes of literature deals only with mental processes (AIF I No. 511: 24).

The search for authentic Buddhism begins from the "source" - in Nepal, where the head of the Department of Buddhist Studies at the University of Tribhuvan recommended Khenpo Ramesh as a specialist not only in theoretical but also practical Buddhism: and this professor, the dean ... I told him, I know that here the Westerners are considered fools and are being lied from the station, any spirituality is here ... and because the West is pretty naive ... but like in everything, in every science and in any profession, such as in medicine there are many doctors, but five of those are good... And so I went and told him, tell me who is good, and he gave me four names, one of them was Khenpo Ramesh (AIF I No. 511:24).

Khengpo Ramesh holds a PhD from the University of Varanasi, India, having defended a dissertation devoted to the Heart Sutra and taught at several universities in India and Nepal. Besides being a monk himself, his father is also a Buddhist practitioner who, at 35, went into a retreat. He is considered to be a person who completely controls the entire autonomic nervous system, which, 
according to our science is completely impossible (AIF I No. 511: 25). This "living example" of realisation of the ideas of Buddhism is also an inspiration for the followers of Khenpo Ramesh.

Hence, the group is formed by interested practitioners. Other incentives are the visits of Khenpo Ramesh in Bulgaria which date back to 2004-2005, with a frequency of once or twice a year and including the ideas of establishing a permanent residence and spending half a year in the country.

According to Khenpo Ramesh, his Bulgarian followers are people with a very different culture, but they could slowly understand Buddhism. On the other hand, Buddhism spreads in the West because of the desire of people to be happy and to avoid suffering:

So people are now checking and they feel the way of Buddha is very convenient, very easy to understand and it is following the truth... So here Bulgarian people, also they are interested in Buddhism, they feel something special, they are and slowly they are listening, thinking, and then apply into mind, I think so, they will understand (AIF I No. 511: 35).

Apart from the fact that the community relies on an authentic teacher, they managed to build a monastery as a branch of the one in India. It was registered in 2015 under the Religious Denominations' Act, presuming to attract several monks from India.

\section{Palyul, Nuingma}

Palyul tradition is one of the six sub-schools of the Tibetan Nyingma tradition and the oldest of the five Buddhist schools. Palyul monastery was founded in 1665 in the province of Kham by Kunzang Sherab. Its centre today is the Namdroling Monastery in southern India, led by H. H. Karma Kuchen Rinpoche (The Fourth Pema Norbu Rinpoche 2016). The school has various centres around the world, while the Bulgarian one is one of the few in Europe $e^{4}$, officially acknowledged as its international representatives.

The Centre in Bulgaria was founded in 2011 and supported by Pema Rinpoche, who is one of the main teachers of the school in Bulgaria. Palyul in Bulgaria is an example of a school organised around the idea of systematic training in Buddhism not only by authentic teachers but also by trained local followers. It offers a training program in which anyone can join in a few periods during the year. 
The Centre organises an introduction in Buddhism which presents its philosophy and development to those unfamiliar with these themes. In addition, there are courses in meditation shine (residing in peace) and analytical meditation, dealing with current topics such as love, relationships, dealing with anger and strong wishes, etc. Meditation consists of four main parts: acquaintance with a text given by the lama, contemplation, meditation, and yoga. The introductory course continues for about six months, after which the participants can join the annual learning cycles, meet the Lama personally and the adept to receive the necessary to be able to start practicing in a group (AIF I No. 511: 66). The Ngondro group, as first and introductory level, consists of six cycles, each lasting for two months, repeated annually. This cyclicity allows new people to join the school. The next level, which is not actively practiced in the centre but practiced by the members of the sangha, is tsa-lung ${ }^{5}$, a secret Tibetan yoga which one can only practice with the direct guidance of an authentic teacher. Higher practises are also passed on personally to the follower by his teacher. Tsa-lung is followed by other practises to reach the so called three-year retreat that can only be passed under the guidance of a teacher.

The main event for the school, however, is in Germany, at the European Palyul Retreat Centre, where training is given annually for each of the classes. This means that anyone who is seriously practicing and wants to receive teachings should go there (AIF I No. 511: 66). Every summer in the last six years a summer retreat on the Black Sea coast is also being organised and a Palyul teacher being invited.

Another activity of the centre is the celebration of the so called special days: Guru Rinpoche's Day, the $10^{\text {th }}$ day of the Tibetan calendar; the medical guru - on the $8^{\text {th }}$ day; the day of Dakini $-25^{\text {th }}$ day. Each month the three pujas are celebrated (varying on different days according to the Western calendar). An important practice is sang offering - smoke offering, a central practice for the centre. It is a basic practice of all Pema Rinpoche's centres: it removes obstacles both in personal context and during practice, and obstacles related to the centre, the sangha, the surroundings, of any nature. Once a month, a phowa takes place - a transfer of consciousness. Practices aimed at more specialised level, requiring higher experience, are $c h o^{6}$ and rigdzin dupa $\mathrm{a}^{7}$.

The training, moreover, includes periodic visits of Palyul teachers for delivering lectures. They are open to both various Buddhist communities in the country and to the general public as well (advertised on Facebook, etc). 
On the Path of the Buddha - Specifics and Distribution of Buddhism in Bulgaria

\section{Gelug}

Gelug (also known as the Yellow Hats) is a school in Tibetan Buddhism founded by Je Tsongkhapa (1357-1419) in Ganden Monastery, Lhasa region, Tibet. Thanks to the union with the Mongols, it is the largest and most influential Buddhist school in Tibet since the late $16^{\text {th }}$ century, and the Dalai Lama - the spiritual leader of the country.

Gelug in Bulgaria began spreading in the towns of Vratsa (since 2010) and Sofia (since 2011) around the teachings of Geshe Tenzin Tamding (Monasterio Universidad Chu Sup Tsang 2016), a president of Chu Sup Tsang foundations, sent personally by Dalai Lama to preach Buddhism around the world. He visits Bulgaria annually since 2010.

In a centre in Spain Geshe Tenzin Tamding met a Bulgarian whose invitation brought him to the country: After some time he invited me to go to his country, I asked him where he came from and he answered "from Bulgaria". I said, "Okay, we'll see"... and three years passed like that. In the third year he bought me a plane ticket and took me to Bulgaria (personal archives).

Other teachers visiting the country are Tritul Rinpoche and Geshe Lobsang Yeche, delivering lectures based on the book of $\mathrm{P}$. Rinpoche "Liberation In the Palm of Your Hand" (Rinpoche 2006).

The founder of the group in Sofia tells about the history of the group in Bulgaria:

I had a catering company for 22 years. After that meeting, within two years, I sold my business, started practicing actively, learnt Spanish, and began translating books, the first we published in 2014. We created a group to gather once a week and study literature recommended by the teachers. We also started a program group of ten years long course in philosophy, psychology, epistemology, etc., similar to the program in the Tibetan monasteries (AIF I No. 511: 92).

Since 2017, a course devoted to the five basic texts studied in the Tibetan monasteries began in Sofia: Tsema Namdrel - the valid knowledge (Logic), Parchin - unlimited wisdom (aimed at managing the negative attitudes), Madhyamika - the philosophy of the middle way and the Buddhist understanding for emptiness and Vinaya or Ethics (the teachings are passed by the Nagarjuna lineage $)^{8}$. The main practices of the group in Sofia are reading the 
texts delivered by the teachers and performing analytical meditations over them. Other practices for the group include taking refuge, mandala, ngöndro, repetition of mantras.

\section{Bon Tradition (Between Shamanism and Buddhism)}

Bon Buddhism is associated with the ancient religion Bon and is already recognised in Tibet as the fifth Buddhist school. According to the Bon followers, it penetrated into Tibet centuries before Buddhism when the latter replaced it in the $8^{\text {th }}$ century. It is believed to be originating from a country known as Zhangzhung kingdom that was conquered and assimilated by Tibet ${ }^{9}$. The main specificity of Bon Buddhism is the belief that Buddha Shakyamuni is not the first to achieve enlightenment, but only one of a series of Buddhas, the first of which is Tonpa Shenrab ${ }^{10}$, the creator of Bon.

Bon Buddhism was distributed in the West in the 1980s by Tenzin Rinpoche, the establisher of the international Bon community, whose base is nowadays found in the USA ${ }^{11}$.

The modern Bon Buddhism, including the one spread in the West, is centred around the dzogchen teachings. In Bulgaria, Bon Buddhism is represented by a small community. It penetrated from Mexico about six years ago, through a Bulgarian lady and her Mexican husband: at a seminar in Pueblo ... I met Lama Tenzin Wangyal and ... at that moment I saw all my quests summarized in a very rational way ... with a very good philosophical rationale and very concrete results (AIF I No. 511: 50).

They practice every day, and after their return to Bulgaria form a small group around which the main activity of Bon Buddhism in the country is organised today. The main group meditation is held once a week, where besides the permanent four-five followers whom one can them every time there are also incoming, we sometimes reach ten to twelve people during meditation, while on seminars we reach around thirty (AIF I No. 511: 55).

The meditation practised in Bon-dzogchen is similar to the one of Zen, which does not deal with visualisations and symbols. It aims at achieving a state of immobility and silence, observation of thoughts and feelings and basically recharging at the physical and mental levels.

The numerous Bon Centres in Europe also facilitate visits by lamas - also in Bulgaria, mainly from the European Centre in France (Geshe Korden Lundrup 
Gyaltsen). The lamas in Bon are open to the technologies and much of their teachings are also available through online seminars without any payment. Bon Buddhism attracts through its tolerant attitude, the cohesion between the lamas - they can have different centres and each centre can be named differently but they are a very cohesive community (AIF I No. 511: 52) and a lack of power tension.

The community is not registered under the Law of Denominations, not only due to the lack of enough followers but also because of the conviction of the Bulgarian adepts that it is not a religion, but rather a philosophy and a way of life. The lack of ideas concerning the distribution of Bon and the organisation of a stable community is based on the notion that the followers need neither the Lama nor the Sangha nor the Buddha. The community is necessary as a means of support, until you can feel that you are able to do it by yourself. This specificity allows the comparison of this particular Buddhist tradition with the new spirituality, being close to it.

\section{Japanese Buddhism - Zen (Between Buddhism and Martial Arts)}

Zen is a Mahayana Buddhism that is believed to have originated in the $7^{\text {th }}$ century in China and subsequently spread to Vietnam, Korea, and Japan to enter the United States and Europe in the early $20^{\text {th }}$ century. Zen began to spread to Japan in 1191 distributed by the monk Eisai, who is considered the founder of the Rinzai Zen School. Rinzai Zen ideas became popular mainly within the samurai circles and the military class that practised martial arts.

Zen Buddhism penetrated in Bulgaria namely in relation to aikido and the work of Tenzen Dozen Osho, an aikido teacher (known as Sensei Edward Germanov) and Zen priest. The history of Zen in Bulgaria is thus directly related to its founder's life path. The community is built on the ideas of its teacher Toyoda Shihan, reflecting the model of existence of the human as a versatile personality: Ken-Zen-Sho or martial art, spiritual development (Zen) and aesthetic development of the personality (calligraphy or ikebana). After completing courses in Chicago and Hawai, Edward Germanov came back to Bulgaria attempting to popularise Zen: 
I've been trying to organize a Zen group for a very long time. However, according to the specifics of Zen practice, it is very dull for the people on the street, one doesn't notice any progress for a long time, has to deal with extremely incomprehensible things ... which are completely absurd for the standard person (AIF I No. 511: 41).

Thus, the Zen group was formed around core students, and in 2013 it also registered as a religious community. Today, Zen's activity is centred around an aikido dojo. In addition, Tenzen Dozen Osho is an authorised Zen priest who can perform various ceremonies (weddings, christenings, funerals), and also possesses the title rhosi - a bearer of the so-called dharma heredity (AIF I No. 511: 42), Buddha's direct blood successor.

The Zen School is built on a strictly fixed and traditional program that has not changed for millennia. It includes weekly practices like $z a-z e n$ (sitting meditation) and misogi; a beginners' course, which takes place twice a year and provides basic information; Seshin (twice a year) - a seven-day meditation. The practice of misogi: misogi, this must be understood as two main activities: one is breathing, the other is sound or echo. When you learn to breathe, you can produce a sound, the sound has built, according to our understanding, all that you and we can see ... Breathing and shouting alter our, so to say, inner essence (AIF I No. 511: 43). Occasionally, practices of ikebana or calligraphy are also held.

Teachers are being invited on a regular basis, but due to the fact that the teacher is holding a very high level in the school worldwide, there is no need to invite people every year (AIF I No. 511: 43). Therefore more attention is paid at the various Zen activities, such as misogi (for which a Japanese teacher is being invited), hodjo and others.

As the community is only centred in Sofia, the main aim today is the transfer of knowledge in a narrow circle, based on personal relationships, with followers who prove themselves to be worthy and devoted to the idea of working on yourself. The lack of wider interest in the Zen practice is also conceived as a reluctance to change: Zen is advertised on our website. However, no one has come from the website to say, I read it on the website and want to subscribe... Look, people prefer to talk, people prefer to read and then post on Facebook. However, when you have to stay an hour with yourself, to be able to look at yourself and see both your negative and positive traits and start working with yourself for a change, then people don't like to do it (AIF I No. 511: 44). Therefore, Zen is still largely unpopular worldwide. 


\section{Buddhism in Bulgaria: Trends and Directions for Its Future Research}

Buddhism penetrates in Bulgaria in the context of the religious transformations of post-socialist space and the "opening" of the spiritual market along with a number of other eastern religious ideas. Here it evolves in line with its global distribution processes in the Western world: in pluralistic forms, as transnational communities (cyber-sanghas), around mobile and periodically visiting the country teachers, in the form of dynamic groups. The pluralist forms of Buddhism are evident in the different tendencies in the search of the "real" Buddhism in Bulgaria. They range from dissatisfaction and disappointment with its state in its original environment (in Bhutan) $)^{12}$, to the vision of its simplistic presentation in the West (and in Bulgaria) (AIF I No. 511: 29). Among all its forms in Bulgaria (Karma Kagyu, Drukpa Kagyu, Ningma, Gulug, Bon and Zen), it is the "Western" Buddhism transmitted by the "Western" teacher - Lama Ole Nydahl, that turns out to be the most successful. The good organisation of the community supports this as well.

At present, Buddhism in Bulgaria is practised by relatively small communities, which does not require a special strand for its study, as is the case in a number of countries in Western Europe, USA and Australia. It can be studied, therefore, in the context of the new religious movements/new spirituality. Its specifics, however, require its serious study not only in the forms in which it is spreading in the West but also in the cultural context in which it emerges and develops (India, Nepal, Tibet). This could provide a more in-depth answer to the question of whether and to what extent a religious system that has emerged in a very different cultural environment in a particular historical context can be understood.

The practice of Buddhism in Bulgaria is considered by its followers either a great challenge (this is a nice country with ... messed people, but this is a challenge because there is plenty of things for a person to work on (AIF I No. 511: $45)$ ) or a great chance. Bulgaria is a country that still does not suffer to a large extent from the negative effects of globalisation, which, according to Lama Ole Nidhal, is a good prerequisite for the spread of Buddhism (AIF I No. 511: 14). The financial situation, on the other hand, does not contribute to establishing large centres (except some centres of the Diamond Way) by authentic teachers, as is the case in a number of Western European countries. 
Buddhism in Bulgaria can be studied as a response to specific needs of the Bulgarian society or in its functional aspect. Thus, we can gain insights regarding its influence on the Bulgarian culture, the extent to which it is modified by the local context, as well as answer the question about how universally applicable it is. So far, the study has shown that it is well received among people related to science, psychology, business, by those seeking new forms of spirituality and specific answers to questions related to happiness, lack of suffering, etc. ${ }^{13}$

Although this issue is the subject of further research, I could already outline some of its core functions. Buddhism, in the first place, claims to provide methods for solving specific problems faced by Western societies: over-rationalisation, selfishness, lack of values, and so on. In this context, it is presented, for example, as a complete opposition to selfishness: egoism [here in the West] is very strong. Egoism is actually totally opposite of Buddhism, ya...here people believe in materialistic development ... They think, if we have too much money we are ok. Actually it's not like that. Money is needed but main thing is need you pure mind, ya, to establish the real human society we need the clear mind. Compassion comes from mind not from money (Khenpo Ramesh, AIF I No. 511:38).

In addition to providing specific problem-solving methods (meditations and various practices), it is also applied in the Western psychology and psychoanalysis through its methods for managing mental processes. Even psychologists claim that Western psychology borrows its basic ideas from Buddhism: I am a psychologist ... and I know that since Hegel everything has been inspired by Buddhism (AIF I No. 511: 24). It is not by chance that it aims, primarily through meditation, to unload the mind from stress and the constant need of the Western people to make decisions and react quickly to specific situations. The direct application of Buddhism can thus be an alternative to expensive therapies, but understood correctly: here in the West they like to twist it ... some of the things ... are presented in another way. Unfortunately, quite fragmented, fragmented concepts and techniques are being taken out in the West, and does not represent Buddhism. Buddhism is a unified system (AIF I No. 511:24).

Buddhism is a complex philosophical-religious system derived from a radically different (from the European) cultural system, which implies its adaptation and modification when applied in a new environment. It is not widely distributed in Bulgaria, but it has a specific application and is often associated with science, psychology, art, etc., characteristic of the Western cultures spheres. All these particularities should be taken into account when analysing its functional aspects and its analysis by the humanities and social sciences. 
On the Path of the Buddha - Specifics and Distribution of Buddhism in Bulgaria

\section{Aknowledgements}

The fieldwork was completed in the framework of the project "Distribution and Specifics of Buddhism in Bulgaria" (DFNP-169/13.05.2016), funded by the Program for support of young scientists, Bulgarian Academy of Sciences (project leader - Svetoslava Toncheva, BAS, supervisor - Ekaterina Anastasova, BAS, consultant - Lyudmila Klasanova, Sofia University).

\section{Notes}

1 Under the term "West" in the context of the distribution of Buddhism outside the region of its traditional distribution in the modern research one understands Europe, America (North and South) and Australia as an opposition of the "East".

2 More information regarding the life of Ole Nydahl can be found in his book "Entering the Diamond Way" (2001).

3 A title awarded to the monks in the schools of Nyingma, Sakya and Kagyu after graduating a nine years' curse in Buddhist philosophy.

4 Other centres in Europe are located in Germany and UK.

5 From Tibetan: tsa - channels, lung - wind, energy.

6 From Tibetan: spiritual practice also encountered in Nyingma and Kagyu, known as elimination of the ego.

7 Esoteric lama-practice.

8 Nagarjuna (around. 150-250) is one of the six great philosophers in Buddhism, given profound comments on Buddha's teachings.

9 Possibly a region in Tibet not far from the mount Kailash.

10 According to legends he was born 18000 years ago in the country of Olmo Lungring.

11 Founder of Ligmincha International, available at http://www.ligmincha.org/index. $\mathrm{php} / \mathrm{en} /$, last accessed on 08.11.2016.

12 Impressions of followers of Lama Ole Nydahl after their visit to Bhutan.

13 In the overall profile of the followers of Buddhism there are a variety of professions, but dominate those in the business sphere, psychology, the IT sector, education (mainly physics and chemistry). Leading figures in the organization of the groups are related to physics and psychology. 


\section{Archive Materials}

AIF I No. 511 (recorded by Svetoslava Toncheva)

FnAIF No. 2919 (recorded by Svetoslava Toncheva)

\section{References}

Barker, Michelle \& Rocha, Cristina 2011. Introduction. In: Rocha Cristina \& Michelle Barker (eds.) Buddhism in Australia, Traditions in Change. New York: Routledge, pp. 1-19.

Baumann, Martin 2001. Global Buddhism: Developmental Periods, Regional Histories, and a New Analytical Perspective. Journal of Global Buddhism, Vol. 2, pp. 1-43.

Diamond Way 2016. Available at http://www.diamondway.bg/, last accessed on 10.11.2016.

Face Tibet. Available at http://facetibet.com, last accessed on 20.10.2016.

Geshe Korden Lundrup Gyaltsen. Available at https://www.facebook.com/khorden, last accessed on 20.10.2016.

Ligmincha International. Available at http://www.ligmincha.org/index.php/en/, last accessed on 08.11.2016.

Matraux, Daniel 2003. The Soka Gakkai in Australia: Globalization of a New Japanese Religion. Journal of Global Buddhism, Vol. 4, pp. 108-143. - Missing in the text

Monasterio Universidad Chu Sup Tsang 2016. Available at https://fundacionchusuptsang. org/, last accessed on 10.11.2016.

Prebish, Charles 1993. Two Buddhisms Reconsidered. Buddhist Studies Review, 10 (2), pp. 187-206.

Rinpoche, Pema 2006. Liberation in the palm of your hand. Boston: Wisdom Publications. The Fourth Pema Norbu Rinpoche 2016. Palyul Ling International 2016. Available at http://www.palyul.org/index.htm, last accessed on 05.11.2016.

Togdens 2016. Available at http://www.tendokandojo.com/ZEN.html, last accessed on 20.11.2016.

Virtbauer, Gerald 2012. The Western reception of Buddhism as a psychological and ethical system: developments, dialogues, and perspectives. Mental Health, Religion \& Culture, 15 (3), pp. 251-263. DOI: 10.1080/13674676.2011.569928.

Yong, Amos 2008. Tibetan Buddhism Going Global? A Case Study of a Contemporary Buddhist Encounter with Science. Journal of Global Buddhism, Vol. 9, pp. 1-26. 